\title{
Long-Term Biosanitation by Application of Coniothyrium minitans on Sclerotinia sclerotiorum-Infected Crops
}

\author{
M. Gerlagh, H. M. Goossen-van de Geijn, N. J. Fokkema, and P. F. G. Vereijken
}

First, second, and third authors: DLO Research Institute for Plant Protection, IPO-DLO, P.O. Box 9060, 6700 GW Wageningen, the Netherlands; fourth author: Centre for Biometry Wageningen, CPRO-DLO, P.O. Box 16, 6700 AA Wageningen, the Netherlands. Accepted for publication 26 October 1998.

\begin{abstract}
Gerlagh, M., Goossen-van de Geijn, H. M., Fokkema, N. J., and Vereijken, P. F. G. 1999. Long-term biosanitation by application of Coniothyrium minitans on Sclerotinia sclerotiorum-infected crops. Phytopathology 89:141147.

The effect of the fungal mycoparasite Coniothyrium minitans applied as a spray to crops infected with Sclerotinia sclerotiorum (causal agent of white mold) on contamination of soil with S. sclerotiorum sclerotia was studied in a 5-year field experiment. Sclerotial survival also was monitored during two subsequent years, when the field was returned to commercial agriculture. In a randomized block design, factorial combinations of four crops and three treatments were repeated 10 times. Potato (Solanum tuberosum), bean (Phaseolus vulgaris), carrot (Daucus carota), and chicory (Cichorium intybus), which are all susceptible to S. sclerotiorum, were grown in rotation. Plots were treated with C. minitans or Trichoderma spp. or were nontreated (control). Crops were rotated in each plot, but treatments were applied to the same plot every year. After 3 years during which it showed no effect on sclerotial survival, the Trichoderma

fourth and fifth years of the trial. The effect of treatments was monitored in subsequent seasons by counting apothecia as a measure of surviving $S$. sclerotiorum sclerotia and scoring disease incidence. Trichoderma spp. did not suppress S. sclerotiorum, but C. minitans infected at least $90 \%$ of $S$. sclerotiorum sclerotia on treated crops by the end of the each season. C. minitans lowered the number of apothecia compared with the other treatments during the second year after the bean crop. C. minitans reduced the number of apothecia by $\approx 90 \%$ when compared with the control and Trichoderma spp. treatments and reduced disease incidence in the bean crop by $50 \%$ during the fifth year of the trial, resulting in a slightly higher yield. In 1993, but not 1994, a single spray with C. minitans was nearly as effective at reducing apothecia as three sprays (monitored in 1995). The final population size of sclerotia in soil at the end of the 7-year period was lower in all C. minitans plots than at the beginning of the trial, even in plots where two highly susceptible bean crops were grown during the period. The results indicate that the mycoparasite $C$. minitans has the potential to keep contamination of soil with sclerotia low in crop rotations with a high number of crops susceptible to S. sclerotiorum.
\end{abstract} spp. treatment was replaced by a single spray with $C$. minitans during the
Sclerotinia sclerotiorum (Lib.) de Bary, causal fungus of white mold, is one of the most common broad-spectrum pathogens of the temperate zone. S. sclerotiorum attacks nearly all broad-leaved agricultural and horticultural crops. S. sclerotiorum sclerotia can survive for more than 5 years in soil (2). Therefore, few crop rotation systems can prevent damage once soil has been contaminated by sclerotia.

In high-value horticultural crops, fungicide sprays to prevent white mold are standard practice, but in arable crops, such as rapeseed and sunflower, preventative fungicide sprays are not economically feasible. Because of environmental considerations, new disease management strategies are needed for both situations. Biological control is a promising alternative to fungicide application, but it is normally not as effective as chemical controls when used in the same ways to prevent germination of and infection by $S$. sclerotiorum at its infection court (7). Experiments with applications of biocontrol agents (BCAs) to protect crops against infection generally have shown discrepancies between laboratory and field results, sometimes due to environmental factors, as discussed by Hannusch and Boland (12) in the case of white mold. Other researchers $(6,14,18)$ have tried to prevent direct infection of roots or seedlings by germinating $S$. sclerotiorum sclerotia in soil. Seed dressings with BCAs or applications at seed-placement sites are preferable economically, because they limit the quantity of BCA needed and application can be timed to coincide with other cultural

Corresponding author: M. Gerlagh; E-mail address: M.Gerlagh@IPO.DLO.NL

Publication no. P-1998-1209-02R

(C) 1999 The American Phytopathological Society operations. BCAs designed to infect and kill sclerotia in situ when incorporated into soil have trouble reaching a sufficiently large proportion of sclerotia (1). Several authors, however, have reported promising results of application to soil of Coniothyrium minitans Campbell, a fungal mycoparasite (coelomycetes) that is highly specialized on Sclerotinia spp. $(4,17,19,25)$. Reducing the number of sclerotia incorporated in soil is an alternative method of improving biological control. One approach is to apply $C$. minitans to a diseased crop, which facilitates contact between the survival structures of the pathogen and the BCA. The current paper presents the results of an investigation of the effect of spraying crops naturally infected by $S$. sclerotiorum with $C$. minitans spore suspensions on survival of sclerotia and persistence of effects in the same plots for up to 6 years. Preliminary results have been published previously $(8-10)$.

\section{MATERIALS AND METHODS}

Field plots. A 5-year trial (1990 to 1994) was conducted in calcareous sandy loam soil (fluventic Eutrochrept [21]) naturally contaminated with $S$. sclerotiorum at the Regional Research Centre (de Waag) in the Dutch North-East Polder. The trial was laid out in a $3 \times 4$ factorial design with 10 replicate blocks. A 4-year crop rotation was practiced, with a succession of potato (Solanum tuberosum L.), bean (Phaseolus vulgaris L.), carrot (Daucus carota L.), and chicory (witloof, Cichorium intybus L.) in $5 \times 5$-m plots and all crops present at the beginning of the rotation. Treatments consisted of three sprays with $C$. minitans or Trichoderma spp. and a nontreated control. Plots were separated by a 4-m-wide buffer of maize (Zea mays L.), surrounding each plot to prevent interplot interference from $S$. sclerotiorum and antagonists. The 12 combi- 
nations of crops and treatments were randomly arranged within each block. Crops were rotated in plots during the experimental period, but the $C$. minitans and Trichoderma spp. treatments were applied to the same plots for 5 and 3 years, respectively. Because the Trichoderma spp. treatment failed to provide any effect, it was replaced in the fourth and fifth years by a single spray application of $C$. minitans, applied at the same time as the third spray application in the C. minitans-treatment plots. After 5 years, all treatments were discontinued, but observations were made in years six and seven, when potato and chicory, respectively, were grown commercially in the entire field.

Beans and carrots were grown in a flat field, and potatoes and chicory were grown on ridges according to normal agricultural practices in the Netherlands. Fungicide sprays were omitted to avoid any interference with $S$. sclerotiorum epidemics. However, an oomycete-specific fungicide (Cymoxanil) was applied weekly $\left(250 \mathrm{~g}\right.$ a.i. $\mathrm{ha}^{-1}$ ) to control potato late blight. Row spacing was $50 \mathrm{~cm}$ for bean and carrot crops. Chicory was grown in a double row per ridge, with $5 \mathrm{~cm}$ between the center of the ridges. Potato was planted with $75 \mathrm{~cm}$ between ridges. Cultivars and sowing dates are given in Table 1.

Treatments. Isolates of $C$. minitans originated from soil baited with sclerotia of $S$. sclerotiorum (10). For spray treatments, four C. minitans isolates (C10A, C15, IVT1, and IVT5) were combined in equal amounts (weight of air-dried culture). C10A and IVT1 develop pycnidia very early (type 1 of Sandys-Winsch et al. [20], coded as C10A and G8, respectively; IVT1 is available at the Centraal Bureau voor Schimmelcultures [CBS], Baarn, the Netherlands, culture 148.96). C15 and IVT5 are mycelial types that produce less abundant pycnidia later (type 5 of Sandys-Winsch et al. [20]; coded as C15 and G9, respectively; CBS cultures 147.96 and 150.96, respectively).

Inoculum of $C$. minitans was produced by immersing $400 \mathrm{~g}$ of dry, unprocessed oats overnight in tap water. Surplus water was drained, and moist oats were sterilized twice (24-h interval) in 3liter mushroom-spawn bags (Sylvan, Horst, the Netherlands). The

TABLE 1. Crop and treatment data

\begin{tabular}{|c|c|c|c|c|c|c|}
\hline Crop $^{u}$ & Category & 1990 & 1991 & 1992 & 1993 & 1994 \\
\hline \multirow[t]{9}{*}{ Potato } & Cultivar & Surprise & Surprise & Surprise & Surprise & Surprise \\
\hline & Date of planting & 9 April & 15 April & 8 May & 15 April & 3 May \\
\hline & Apothecia counts ${ }^{\mathrm{V}}$ & 27 June & 26 June & 15 July & 15 July & 20 July \\
\hline & & 6 July & 9 July & 29 July & 28 July & 2 August \\
\hline & & 17 July & 17 July & & 6 August & \\
\hline & & 1 August & 23 July & & 17 August & \\
\hline & Sprayingw & 6 July & 9 July & 15 July & 15 July & 20 July \\
\hline & & 1 August & 23 July & 29 July & 28 July & 2 August \\
\hline & & 15 August & 7 August & 12 August & 6 August & 17 August \\
\hline \multirow[t]{15}{*}{ Bean } & Cultivar & Groffy & Groffy & Groffy & Groffy & Berna \\
\hline & Sowing date & 20 May & 27 May & 15 May & 25 May & 10 May \\
\hline & Apothecia counts ${ }^{\mathrm{V}}$ & 1 August & 26 June & 15 July & 28 July & 20 July \\
\hline & & 8 August & 20 August & 29 July & 6 August & 2 August \\
\hline & & 15 August & 28 August & & 17 August & 17 August \\
\hline & Sprayingw & 15 August & 20 August & 15 July & 28 July & 20 July \\
\hline & & 23 August & 28 August & 29 July & 6 August & 2 August \\
\hline & & 7 September & 5 September & 12 August & 17 August & 17 August \\
\hline & Disease scoring ${ }^{\mathrm{x}}$ & 8 August & 20 August & 29 July & 6 August & 2 August \\
\hline & & 15 August & 28 August & 12 August & 17 August & 17 August \\
\hline & & 23 August & 5 September & 26 August & 31 August & 30 August \\
\hline & & & $\begin{array}{l}17 \text { September } \\
1 \text { October }\end{array}$ & & 14 September & \\
\hline & Sampling of sclerotia ${ }^{y}$ & 23 August & $\mathrm{IN}^{\mathrm{z}}$ & 12 August & 31 August & 30 August \\
\hline & & 7 September & & 26 August & 14 September & 13 September \\
\hline & & 28 September & & 8 September & 29 September & \\
\hline \multirow[t]{8}{*}{ Carrot } & Cultivar & Berlando & Berlando & Berlando & Berlando & Berlando \\
\hline & Sowing date & 3 May & 3 May & 15 May & 25 May & 10 May \\
\hline & Apothecia counts ${ }^{\mathrm{V}}$ & 15 August & 26 June & 12 August & 28 July & 2 August \\
\hline & & 23 August & & 26 August & 6 August & 17 August \\
\hline & & 7 September & & 8 September & 17 August & 30 August \\
\hline & Spraying ${ }^{\mathrm{w}}$ & 23 August & 28 August & 12 August & 6 August & 17 August \\
\hline & & 7 September & 5 September & 26 August & 17 August & 30 August \\
\hline & & 28 September & 17 September & 8 September & 31 August & 13 September \\
\hline \multirow[t]{11}{*}{ Chicory } & Cultivar & Rinof & Rinof & Rinof & Rinof & Focus \\
\hline & Sowing date & 11 May & 21 May & 15 May & 25 May & 10 May \\
\hline & Apothecia counts ${ }^{\mathrm{V}}$ & 1 August & 26 June & 15 July & 28 July & 20 July \\
\hline & & 8 August & 7 August & 29 July & 6 August & 2 August \\
\hline & & 15 August & 20 August & 12 August & 17 August & 17 August \\
\hline & & 23 August & 28 August & 26 August & & 30 August \\
\hline & & & 5 September & 8 September & & \\
\hline & & & 17 September & & & \\
\hline & Sprayingw & 15 August & 20 August & 29 July & 6 August & 2 August \\
\hline & & 7 September & 28 August & 12 August & 17 August & 17 August \\
\hline & & 28 September & 17 September & 8 September & 31 August & 13 September \\
\hline
\end{tabular}

\footnotetext{
u Beans and carrots were grown in a flat field, and potatoes and chicory were grown on ridges. Crops were rotated in the order presented.

${ }^{v}$ Apothecia were counted on soil between the first and second rows and the second-to-last and last crop rows, each along $5 \mathrm{~m}$ of row.

${ }^{w}$ Crops were sprayed with suspensions of Coniothyrium minitans conidia or Trichoderma spp. at 1,000 liters ha ${ }^{-1}$.

${ }^{x}$ Disease incidence was scored in the first, second, second-to-last, and last rows of beans, each along $5 \mathrm{~m}$ of row.

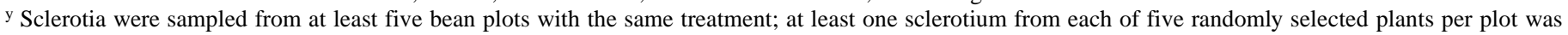
sampled.

${ }^{\mathrm{z}}$ Insufficient number available.
} 
oats in each bag were inoculated with $5 \mathrm{ml}$ of $C$. minitans conidial suspension $\left(10^{7} \mathrm{CFU} \mathrm{ml^{-1 }}\right)$ obtained by flooding a potato dextrose agar (PDA; Oxoid, Basingstroke, England) culture slant of C. minitans with sterile water and gently agitating the surface to liberate conidia from the pycnidia. Bags were shaken three times per week, and after 3 weeks of incubation at $20^{\circ} \mathrm{C}$ in the dark, colonized oats were dried in a sterile air stream at room temperature for $24 \mathrm{~h}$ and stored in a sealed plastic bag at $4{ }^{\circ} \mathrm{C}$ until use. To prepare a conidial suspension, colonized oats were blended with tap water in a household blender for $10 \mathrm{~s}$, left for $30 \mathrm{~min}$ at $4^{\circ} \mathrm{C}$ to imbibe moisture, blended again for $2 \mathrm{~min}$, and filtered by passing through a double layer of cheesecloth. The spore concentration of the resultant suspension was determined with the aid of a hemacytometer, and the suspension was diluted with water when necessary. Approximately $100 \mathrm{~g}$ of dry medium was sufficient for 50 liters of suspension.

Isolates of Trichoderma spp. were obtained from soil baited with sclerotia of $S$. sclerotiorum as previously described (10). Twoweek-old cultures grown in petri dishes on PDA at $20^{\circ} \mathrm{C}$ in the dark were flooded with tap water, and conidia were removed gently from the culture surface. The suspension was passed through a double layer of cheesecloth, and the concentration was adjusted. A mixture of equal amounts (number of petri dishes) of isolates TBV2, T19, T21, and T24 was used.

Treatment sprays consisted of spore suspensions in tap water at a concentration of 1 to $2 \times 10^{6}$ conidia per $\mathrm{ml}$ in the first and second years and $5 \times 10^{6}$ conidia per ml thereafter. Suspensions were applied at a rate of 1,000 liters $\mathrm{ha}^{-1}$ with a propane-driven knapsack sprayer (Azo, Ede, the Netherlands) at $300 \mathrm{kPa}$, using nozzles each yielding $600 \mathrm{ml} \mathrm{min}{ }^{-1}$. The first spray was applied to each crop soon after apothecia of $S$. sclerotiorum appeared. Spraying was repeated twice, usually at $\approx 2$-week intervals. Because the appearance of apothecia depends on canopy closure, apothecia developed at different times in different crops, and spraying time varied accordingly (Table 1). To permit development of apothecia, sprinkler irrigation was begun at the end of June and applied with a maximum of two applications of $\approx 15 \mathrm{~mm} /$ week whenever necessary to keep soil sufficiently moist.

Apothecial development. After the canopy of the earliest crop (potato) had closed, development of apothecia was monitored approximately weekly (Table 1). Apothecia were monitored in two rows per plot. The soil surface between the first and second rows and between the second-to-last and last rows was carefully inspected. Counting was done only when provisional monitoring of a few plots of a crop indicated that a sufficient number of apothecia could be detected, i.e., when most of the plots to be sampled had at least one apothecium. Monitoring was repeated during any field visit when this criterion was met (Table 1). When more than one apothecium was developing on a single sclerotium, the cluster of apothecia was counted as one apothecium, because the interest was in surviving, apothecia-producing sclerotia. Assessment of treatment and crop effects on survival of sclerotia was based on means of the highest number of apothecia-producing sclerotia counted per plot on any of the scoring dates within 1 year.

Sclerotial infection by $\boldsymbol{C}$. minitans. After beginning spray treatments, sclerotia from infected bean crops were regularly sampled to monitor infection by $C$. minitans (Table 1). From at least five bean plots per treatment, five sclerotia per plot were collected from different, randomly selected plants. Sclerotia were surface-sterilized in the laboratory, bisected, and plated on plugs of PDA plus tetracycline at $25 \mu \mathrm{g} \mathrm{ml}^{-1}$ (Sigma-Aldrich Chemie B.V., Zwijndrecht, the Netherlands), as described by Whipps and Budge (24). After 2 weeks of incubation at $20^{\circ} \mathrm{C}$, sclerotia were scored for the presence of $S$. sclerotiorum and $C$. minitans. Sclerotia described as infected by $C$. minitans consisted of those containing a mixture of $S$. sclerotiorum and $C$. minitans and those forming only $C$. minitans colonies (11).

Incidence of white mold and yield. Disease incidence (percentage of diseased plants) was scored in the four rows of plants bordering the two strips monitored for apothecia. Based on the outcome of this score, in 1994 bean yield was assessed by handharvesting the center $2 \times 2 \mathrm{~m}^{2}$ of each plot, drying beans to $10 \%$ relative humidity, and weighing.

Survival of $\boldsymbol{C}$. minitans conidia on healthy crop tissue. To monitor the survival of $C$. minitans conidia on uninfected crops, green healthy leaves of potato and chicory were randomly sampled from each of five plots treated with $C$. minitans, immediately after spraying $C$. minitans and during subsequent field visits. Samples ( $28 \mathrm{~cm}^{2}$ of each of five leaves per plot) were crushed in $5 \mathrm{ml}$ of sterile water, and after serial dilution, a $0.1-\mathrm{ml}$ aliquot was plated on PDA plus tetracycline at $25 \mu \mathrm{g} \mathrm{m}{ }^{-1}$. For each dilution, three petri dishes were inoculated. Petri dishes were incubated in the dark at $20^{\circ} \mathrm{C}$, and colonies of $C$. minitans were counted after 10 days. Number of colony forming units per square centimeter of leaf area was calculated from colony counts in the highest dilutions that still showed colonies in at least 5 of 15 petri dishes per treatment.

Statistical analysis. Loglinear regression was used to analyze observed apothecia counts $(Y)$ in response to several classifying variables: block, treatment, crop, and treatment-crop interaction. In the model, the variance of an observation was assumed to be proportional to Poisson variance. The model is

$\log (\mu)=$ constant + block + treatment + crop + treatment-crop interaction

$$
\text { and } \operatorname{var}(Y)=\phi \mu
$$

where $\mu$ is the expectation of $Y$ and $\phi$ is an unknown dispersion parameter. If $\phi>1$, there is overdispersion compared with Poisson variance. The quasi-likelihood method was used in fitting the loglinear models (16). The criterion for assessing the effects of the various explanatory variables was an $F$ test for the ratio of the mean quasi-deviance for a particular effect to the mean deviance of the rest, which is a current estimate for overdispersion. Pairwise differences between treatment means on the logscale were assessed by $t$ tests. Significant effects $(P<0.05)$ are discussed. In the loglinear model, differences $\left(\Delta_{i j}\right)$ between treatment means on the logscale correspond with ratios $R_{i j}=\exp \left(\Delta_{i j}\right)$ of treatment means on the original scale. To assess the relative treatment effects, estimates of $R_{i j}$ ratios, based on estimates of $\Delta_{i j}$ treatment differences in selected models, were calculated. The selected model contained block, crop, and treatment effects, as well as the crop-treatment interaction for years in which the interaction was significant.

To the observed percentage of white mold diseased bean plants, a logistic model with block and treatment was fitted that assumed variance was proportional with binomial variance. Pairwise differences between treatment means on the logistic scale were assessed by $t$ tests. For data on the percentage of sclerotia infected by $C$. minitans, the standard error of the mean was calculated. The bean yield in 1994 was analyzed by analysis of variance, with block and treatment as explanatory variables. The number of colony forming units of $C$. minitans (logscale) on healthy leaves was analyzed by linear regression, with time, crop, and crop-time interaction as explanatory variables. Statistical analyses were performed using Genstat 5 (release 3, Lawes Agricultural Trust, Hertfordshire, England).

\section{RESULTS}

Numbers of apothecia in rotations and treatments. An overview of the quasi-deviance ratios used to assess the effects of various factors on number of apothecia, the calculated $P$ values of $F$ tests, and the residual mean deviance used as an estimate of the dispersion parameter $(\phi)$ are given in Table 2. Because the $F$ test for interaction was not significant $(P>0.05)$ in 1990, 1991, 1993, and 1996, we concluded that the interaction term was not needed in the model, and the interaction was dropped from the model for these years. The effects of block and crop were highly significant in all years. The block effect was caused by the irregular occurrence of apothecia-producing sclerotia in the field (data not shown). 
In the potato crop, the number of apothecia was generally higher than in the other crops, and in 1991 the difference was more pronounced due to low numbers of apothecia in the other crops (Table 3). In the first and second years (1990 and 1991), there was no effect of treatment on numbers of apothecia, but in 1992 and thereafter, the effect was invariably highly significant $(P<0.001$; Table 2$)$. Details of the effect of treatments on apothecial counts in plots are given in Table 3. Table 4 gives the $P$ values of $t$ tests for significant differences $\left(\Delta_{i j}\right)$ on the logscale and corresponding ratios that differed significantly from 1 for 1992 to 1996.

In 1992 the numbers of apothecia in chicory were high for the Trichoderma spp. and control treatments, higher than any previous counts. All other counts, including the $C$. minitans-treated plots planted to chicory, were low (Table 3). In 1993 high numbers of apothecia were counted in the Trichoderma spp.-treated and control plots planted to potato, which followed chicory in the rotation. In 1994 few apothecia emerged, and the $C$. minitans-treated plots had significantly fewer apothecia than plots treated with Trichoderma spp. or the control planted to bean and chicory (Table 4). Plots planted to bean and chicory and sprayed with Trichoderma spp. contained more apothecia than the control plots. After 1994 no further treatments were applied, but apothecial counts in 1995 and 1996 were continued at the sites of the original plots. The effect of the $C$. minitans treatment persisted after treatments. In 1995 previous treatment with $C$. minitans in three of four crops resulted in low numbers of apothecia compared with the other treatments. In 1996, the last year monitored, $C$. minitans treatment had reduced the number of apothecia to $8 \%$ of the apothecia in the Trichoderma spp.-treated and control plots.
Effect of BCA sprays on sclerotial infection. $C$. minitans sprays resulted in a high percentage of sclerotia infected by $C$. minitans. Treatment with Trichoderma spp. did not result in infection of sclerotia by the antagonist (data not shown). The level of infection by C. minitans was $9 \% 8$ days after the first spray in 1990 and increased over time to $75 \% \approx 1$ month after the first spray (Table 5). In other years, the first sampling date was 4 to 6 weeks after the first spray, and the incidence of infection ranged from 64 to $100 \%$. On the third sampling date in 1992, an additional sample of sclerotia was collected from within stems and pods. These sclerotia had the same percentage of $C$. minitans infection (93\%) as sclerotia superficially present on the diseased crop (Table 5). In 1993 and 1994 sclerotia were sampled after a single application of $C$. minitans to plots treated with Trichoderma spp. in previous years. The interval between spray and first sampling was shorter than for corresponding sampling of plots treated three times, and the percent infection of sclerotia by $C$. minitans was lower. The percentage of infection increased with later samplings. Except for 1990, even the control was infected by $C$. minitans, probably due to incomplete isolation of plots, which facilitated spread of $C$. minitans from treated to control plots. In 1993 percent infection at the third sampling reached $61 \%$ in the control plots.

Disease in crops and effect on bean yield. White mold was negligible in all crops, except bean (data not shown). No effect of spray treatment on disease incidence was found in bean in the 1990 to 1993 crops; therefore, bean yield was not recorded for these years. Of bean plants in 1990,1992 , and 1993,8 to $18 \%$ were infected (Table 6); in 1991 very little white mold developed. In 1994 dis-

TABLE 2. Quasi-deviance ratios for overdispersed loglinear models fitted to apothecia data ${ }^{\mathrm{w}}$

\begin{tabular}{|c|c|c|c|c|c|c|c|c|}
\hline \multirow[b]{2}{*}{ Source } & \multirow[b]{2}{*}{ df } & \multicolumn{7}{|c|}{ Quasi-deviance ratio $^{\mathrm{x}}$} \\
\hline & & 1990 & 1991 & 1992 & 1993 & 1994 & 1995 & 1996 \\
\hline Block & 9 & $8.4 * * *$ & $5.5 * * *$ & $13.6^{* * * *}$ & $13.5^{* * * *}$ & $4.2 * * *$ & $8.0 * * *$ & $6.3^{* * *}$ \\
\hline Treatment & 2 & 1.8 & 1.9 & $27.0^{* * * *}$ & $24.6 * * *$ & $31.2 * * *$ & $39.4 * * *$ & $45.8 * * *$ \\
\hline Crop & 3 & $20.4 * * *$ & $41.6 * * *$ & $64.5^{* * *}$ & $60.0 * * *$ & $43.3^{* * * *}$ & $20.2^{* * * *}$ & $77.3 * * *$ \\
\hline Treatment-crop interaction & 6 & $\ldots{ }^{y}$ & $\ldots$ & $3.1^{* *}$ & $\ldots$ & $2.6^{*}$ & $5.4 * * *$ & $\ldots$ \\
\hline Residual mean deviance & $99(105)^{\mathrm{z}}$ & 2.01 & 1.05 & 1.75 & 1.80 & 1.08 & 2.67 & 2.22 \\
\hline
\end{tabular}

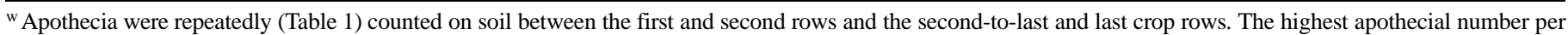
plot for each year was used for analysis. Variance proportional to Poisson variance was assumed.

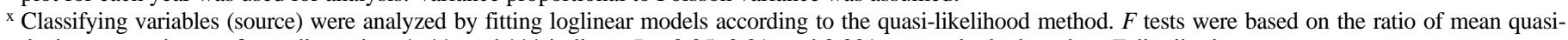
deviance to estimate of overdispersion. * **, and *** indicate $P<0.05,0.01$, and 0.001 , respectively, based on $F$ distributions.

y Interaction was not significant.

${ }^{\mathrm{z}}$ Degrees of freedom for the model with (99) and without (105) interaction between treatment and crop.

TABLE 3. Effect of spraying crops with Coniothyrium minitans and Trichoderma spp. on numbers of Sclerotinia sclerotiorum apothecia in subsequent years

\begin{tabular}{|c|c|c|c|c|c|c|c|c|}
\hline \multirow[b]{2}{*}{ Treatment ${ }^{\mathrm{x}}$} & \multirow[b]{2}{*}{ Crop rotation ${ }^{y}$} & \multicolumn{7}{|c|}{ Number of apotheciaz } \\
\hline & & 1990 & 1991 & 1992 & 1993 & 1994 & 1995 & 1996 \\
\hline \multirow[t]{4}{*}{ C. minitans } & be-ca-ch-po-be & 17 & 3 & 11 & 26 & 4 & 20 & 9 \\
\hline & ca-ch-po-be-ca & 36 & 14 & 11 & 5 & 5 & 6 & 3 \\
\hline & ch-po-be-ca-ch & 21 & 30 & 2 & 11 & 2 & 10 & 5 \\
\hline & po-be-ca-ch-po & 60 & 5 & 9 & 12 & 0 & 10 & 3 \\
\hline \multirow[t]{2}{*}{ Trichoderma 1990-1992 } & be-ca-ch-po-be & 24 & 3 & 122 & 148 & 36 & 148 & 183 \\
\hline & ca-ch-po-be-ca & 36 & 14 & 16 & 11 & 4 & 24 & 3 \\
\hline \multirow[t]{2}{*}{ C. minitans 1993, 1994} & ch-po-be-ca-ch & 23 & 42 & 11 & 16 & 47 & 133 & 50 \\
\hline & po-be-ca-ch-po & 57 & 3 & 10 & 25 & 0 & 16 & 1 \\
\hline \multirow[t]{4}{*}{ Control } & be-ca-ch-po-be & 5 & 3 & 100 & 95 & 14 & 80 & 168 \\
\hline & ca-ch-po-be-ca & 42 & 13 & 11 & 8 & 2 & 110 & 10 \\
\hline & ch-po-be-ca-ch & 40 & 48 & 6 & 23 & 29 & 86 & 40 \\
\hline & po-be-ca-ch-po & 91 & 5 & 6 & 25 & 0 & 13 & 4 \\
\hline
\end{tabular}

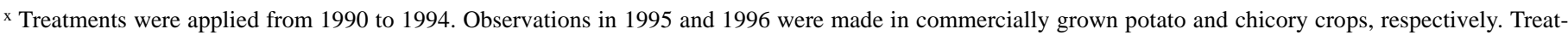
ments consisted of three sprays of $C$. minitans or Trichoderma spp. at $\approx 2$-week intervals, beginning after the first apothecia had been found in a crop. Treatment with Trichoderma spp. was replaced after 1992 by a single spray with $C$. minitans coinciding with the last of three sprays in the $C$. minitans treatment. Spray volume was 1,000 liters ha ${ }^{-1}$ at a concentration of 1 to $2 \times 10^{6}$ conidia per $\mathrm{ml}$ in 1990 and 1991 and $5 \times 10^{6}$ conidia per ml thereafter.

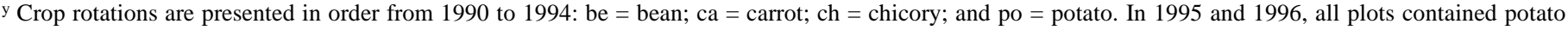
and chicory, respectively.

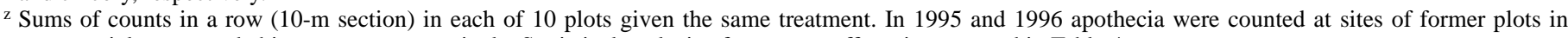
commercial potato and chicory crops, respectively. Statistical analysis of treatment effects is presented in Table 4. 
ease was extremely severe, with more than one-third of the plants infected in the control plots and the plots previously treated with Trichoderma spp. Spraying with $C$. minitans (in previous years) reduced disease incidence by $\approx 50 \%$ (Table 6 ). The average yield of beans in 1994 was 1,237 $\mathrm{g}$ for the Trichoderma spp.-treated plot, 1,397 $\mathrm{g}$ for the control, and 1,452 $\mathrm{g}$ for the $C$. minitans-treated plot. The Trichoderma spp. treatment yielded significantly less than the other two; the difference between the control and $C$. minitans was not significant.

Survival of $\boldsymbol{C}$. minitans conidia on green leaves. Only the population sizes of $C$. minitans on healthy leaves in 1990 were analyzed statistically, because in other years few data per crop were available. The 1990 data showed a significant crop effect $(P<0.01)$. Immediately after spraying, high numbers of viable $C$. minitans

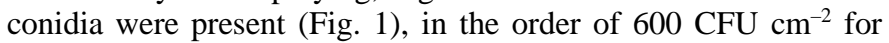
potato and $100 \mathrm{CFU} \mathrm{cm}$-2 for chicory (a difference of 0.7 on the logscale). The number of colony forming units decreased with time $(P<0.001)$ independent of crop, and after 2 weeks, the number had declined 10-fold.

\section{DISCUSSION}

Effect of $C$. minitans application on soil contamination by sclerotia and disease incidence. An epidemic of white mold in a crop such as bean results in production of numerous sclerotia, causing soil contamination that has a prolonged effect on white mold epidemics in subsequent crops. Such an effect was clearly demonstrated in the control treatment of our experiment. Compared with the control, treatment of a diseased crop with $C$. minitans led to a reduction of $\approx 90 \%$ in apothecia numbers in subsequent years but did not lead to a decrease in white mold incidence in crops exposed to the same $S$. sclerotiorum inoculum potential as the control in 1990 to 1993 . The effect of reducing inoculum potential by $90 \%$ was a reduction of $50 \%$ in disease incidence in bean in

TABLE 6. Effect of spray treatments on white mold incidence ${ }^{\mathrm{x}}$ in bean (cv. Groffy) $)^{\mathrm{y}}$

\begin{tabular}{lccccc}
\hline Treatment $^{\mathrm{z}}$ & 1990 & 1991 & 1992 & 1993 & 1994 \\
\hline Coniothyrium minitans & $18.1 \mathrm{a}$ & $2.0 \mathrm{a}$ & $15.0 \mathrm{a}$ & $7.6 \mathrm{a}$ & $18.6 \mathrm{a}$ \\
Trichoderma 1990-1992/ & & & & & \\
$\quad$ C. minitans 1993-1994 & $17.6 \mathrm{a}$ & $1.6 \mathrm{a}$ & $13.7 \mathrm{a}$ & $8.5 \mathrm{a}$ & $35.8 \mathrm{~b}$ \\
Control & $12.0 \mathrm{a}$ & $1.7 \mathrm{a}$ & $8.5 \mathrm{a}$ & $9.9 \mathrm{a}$ & $33.7 \mathrm{~b}$ \\
\hline
\end{tabular}

${ }^{\mathrm{x}}$ Disease incidence is expressed as the percentage of bean plants infected by Sclerotinia sclerotiorum (means of 10 plots, based on counts in four rows [5 m per row] per plot).

${ }^{y}$ Means within columns followed by the same letter do not differ significantly $(P<0.05)$ on the logistic scale (multiple $t$ test).

${ }^{\mathrm{z}}$ Crops were sprayed with spore suspensions of an antagonist soon after apothecia were found. Sprays were repeated two times at $\approx 2$-week intervals. In 1993 and 1994 the three sprays of Trichoderma spp. were replaced by a single spray of $C$. minitans. Spray volume was 1,000 liters ha ${ }^{-1}$ at a concentration of 1 to $2 \times 10^{6}$ conidia per $\mathrm{ml}$ in 1990 and 1991 and $5 \times 10^{6}$ conidia per $\mathrm{ml}$ thereafter. Control $=$ nontreated.

TABLE 4. Relative treatment effects $\left(R_{i j}\right)$ for expected number of apothecia on the original scale, based on treatment differences on the logscale for the selected loglinear model ${ }^{\mathrm{v}}$

\begin{tabular}{|c|c|c|c|c|c|c|}
\hline Treatment comparison (ratio) & Crop $^{w}$ & 1992 & $1993^{x}$ & 1994 & 1995 & $1996^{\mathrm{x}}$ \\
\hline Coniothyrium minitans/Trichoderma spp. & $\begin{array}{l}\text { Potato } \\
\text { Bean } \\
\text { Carrot } \\
\text { Chicory }\end{array}$ & $\begin{array}{l}0.7 \\
0.18 \\
0.9 \\
0.09 \text { *** }\end{array}$ & $\begin{array}{l}0.28 * * * y \\
0.28 * * * \\
0.28 * * * \\
0.28 * * *\end{array}$ & $\begin{array}{l}\mathrm{ND}^{\mathrm{z}} \\
0.11^{* * *} \\
1.3 \\
0.04 * * *\end{array}$ & $\begin{array}{l}0.08 \text { *** } \\
0.6 \\
0.14 * * * \\
0.26\end{array}$ & $\begin{array}{l}0.08^{* * * *} \\
0.08^{* * * *} \\
0.08^{* * * *} \\
0.08^{* * * *}\end{array}$ \\
\hline C. minitans/control & $\begin{array}{l}\text { Potato } \\
\text { Bean } \\
\text { Carrot } \\
\text { Chicory }\end{array}$ & $\begin{array}{l}1.0 \\
0.3 \\
1.5 \\
0.11 \text { *** }\end{array}$ & $\begin{array}{l}0.37 * * * \\
0.37 * * * \\
0.37 * * * \\
0.37 * * *\end{array}$ & $\begin{array}{l}\quad \mathrm{ND} \\
0.29^{*} \\
2.5 \\
0.07^{* * *}\end{array}$ & $\begin{array}{l}0.12 * * * \\
0.8 \\
0.25 * * \\
0.06^{* * *}\end{array}$ & $\begin{array}{l}0.08^{* * * *} \\
0.08^{* * * *} \\
0.08^{* * * *} \\
0.08^{* * * *}\end{array}$ \\
\hline
\end{tabular}

$\checkmark$ Treatments were applied from 1990 to 1994. In 1995 and 1996 apothecia counts were made at sites of former plots in commercially grown potato and chicory crops, respectively. Treatments consisted of three sprays of $C$. minitans or Trichoderma spp. at $\approx 2$-week intervals, beginning after the first apothecia had been found in a crop. Treatment with Trichoderma spp. was replaced after 1992 by a single spray with $C$. minitans, coinciding with the last of three sprays in the $C$. minitans treatment. Spray volume was 1,000 liters ha ${ }^{-1}$ at a concentration or 1 to $2 \times 10^{6}$ conidia per $\mathrm{ml}$ in 1990 and 1991 and $5 \times 10^{6}$ conidia per ml thereafter. Original numbers for compared treatments (pairwise comparison) are given in Table 3.

${ }^{w}$ In 1995 plot values for each crop represent those for crops that would have been grown if the crop rotation had been continued.

${ }^{\mathrm{x}}$ In years without crop-treatment interaction, data for different crops were pooled.

y $\sim$, ***, and $* * *$ indicate $P<0.10,0.05,0.01$, and 0.001 , respectively, based on $t$ distributions for testing treatment differences on the logscale.

${ }^{\mathrm{z}}$ Not defined $(0 / 0)$

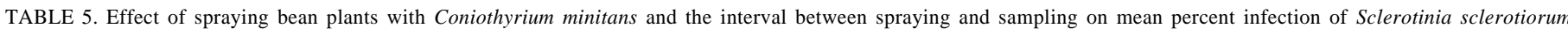
sclerotia by C. minitans

\begin{tabular}{|c|c|c|c|c|c|c|c|c|c|c|}
\hline \multirow[b]{2}{*}{ Sample $^{\mathrm{u}}$} & \multicolumn{2}{|c|}{1990} & \multicolumn{2}{|c|}{1992} & \multicolumn{3}{|c|}{1993} & \multicolumn{3}{|c|}{1994} \\
\hline & Controlv $^{\mathrm{v}}$ & C. minitans $(3 x)^{\mathrm{w}}$ & Control & C. minitans $(3 \times)$ & Control & C. minitans $(1 \mathrm{x})$ & C. minitans $(3 \times)$ & Control & C. minitans $(1 \times)$ & C. minitans $(3 \times)$ \\
\hline First $^{\mathrm{x}}$ & $0(0)^{\mathrm{y}}$ & $9(2.4)$ & $4(4.0)$ & $64(7.5)$ & $20(6.3)$ & $48(4.9)$ & $100(0)$ & $4(4.0)$ & $18(5.8)$ & $100(0)$ \\
\hline Second & $0(0)$ & $76(7.3)$ & $4(4.0)$ & $53(9.4)$ & $28(4.9)$ & $91(5.6)$ & $100(0)$ & $16(9.3)$ & $56(16.3)$ & $98(2.0)$ \\
\hline Third & $0(0)$ & $75(6.4)$ & $2(2.0)$ & $93(4.7)$ & $61(20.5)$ & $81(9.3)$ & $100(0)$ & $\mathrm{ND}^{\mathrm{z}}$ & ND & ND \\
\hline
\end{tabular}

u Five sclerotia were sampled from at least five plots per treatment on three successive dates after the beginning of the spray treatment.

v Nontreated.

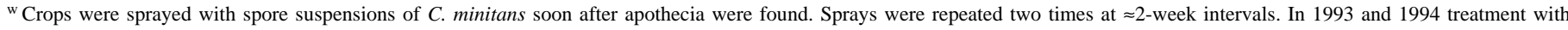
Trichoderma spp. was replaced by a single spray $(1 \times)$ of $C$. minitans that coincided with the last spray in plots treated three times $(3 \times)$ with $C$. minitans. Spray volume was 1,000 liters $\mathrm{ha}^{-1}$ at a concentration of 1 to $2 \times 10^{6}$ conidia per $\mathrm{ml}$ in 1990 and 1991 and $5 \times 10^{6}$ conidia per ml thereafter.

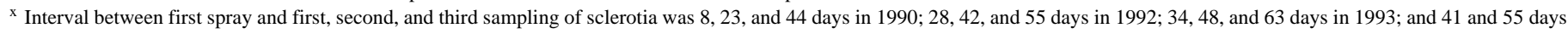
(two samplings only) in 1994 (Table 1), respectively. In 1993 and 1994 the interval between the single spray with C. minitans and samplings was 14,28 , and 43 days, and 13 and 27 days, respectively.

y Standard errors of means are provided in parentheses.

${ }^{\mathrm{z}}$ Not determined. 
1994. The reduction in number of apothecia by $C$. minitans treatments proved consistent and reliable, which compares favorably to biocontrol methods aimed at protection of susceptible crops from direct infection at the infection court (3).

Disease incidence in different crops and inoculum production. The rotation chosen for the experiment was based on the common occurrence of white mold on all four crops in the Netherlands, and the experiment was performed in a field with a history of white mold. With the exception of the bean crop, the natural inoculum in the soil was insufficient to cause significant damage to crops. The low level of natural infection was surprising, because abundant maize pollen, which is known to stimulate infection by pathogens such as Botrytis spp. (5) and presumably Sclerotinia spp. (15), was present. Apothecia were available during the period of maize pollen shed. Additionally, the height of the maize crop caused shading and decreased wind speed, and during dry spells, overhead irrigation was applied, which favored disease. We concluded that among susceptible crops some are infected more severely than others and may contribute more to inoculum carryover. In our trial, only the bean crop contributed to an increase in $S$. sclerotiorum inoculum in soil and was expected to reveal treatment effects in subsequent years.

During the third year of our experiment, very high apothecia counts were found in control and Trichoderma spp.-treated plots that originally were planted to bean in 1990 (Table 3, chicory in 1992) but not in plots sprayed with $C$. minitans. In 1992 a significant treatment effect was observed for the first time (Table 2). Because $C$. minitans was effective only on crops that had sufficient disease levels, there was a strong treatment-crop interaction (Tables 2 and 4). The number of apothecia in the $C$. minitans treatment was $\approx 10 \%$ of that in the control and Trichoderma spp. treatments. In 1991 few apothecia were found in bean plots (Table 3), and disease incidence was low (Table 6). Therefore, production of sclerotia was less than in other years, resulting in relatively low numbers of apothecia in chicory in 1993 and the absence of a treatment-crop interaction in 1993 (Tables 2 and 4).

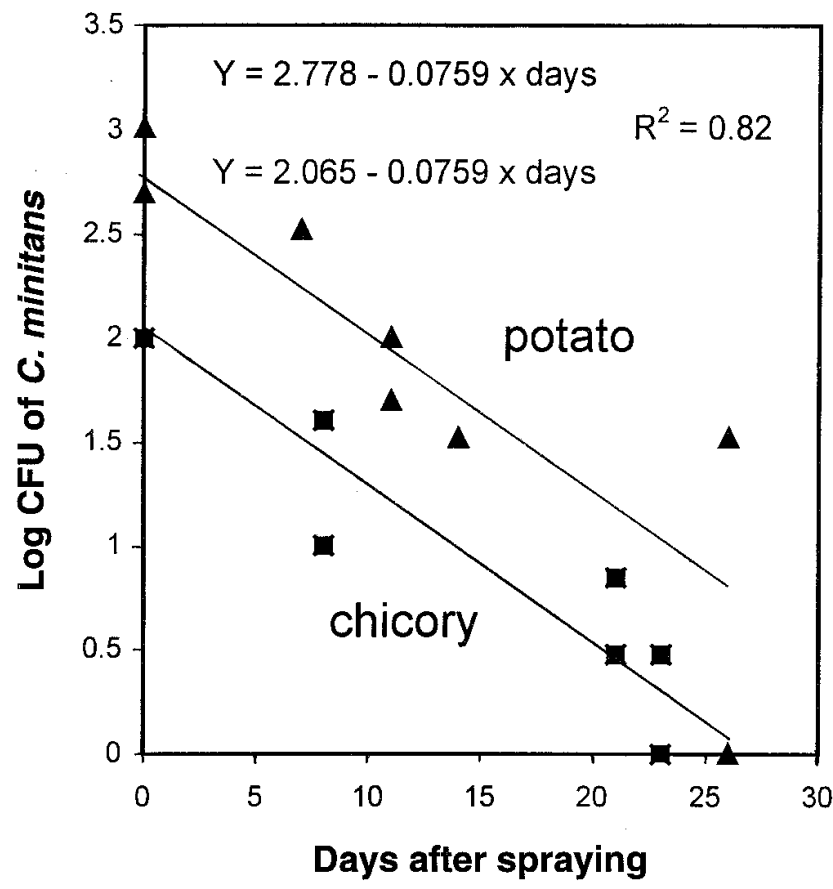

Fig. 1. Population size of Coniothyrium minitans (logscale) on green leaves of potato and chicory at various times after last application of $C$. minitans. Sprays consisted of spore suspensions of 1 to $2 \times 10^{6}$ conidia per ml applied at 1,000 liters $\mathrm{ha}^{-1}$. Values are means of five samples per treatment. Data were analyzed by linear regression of $\log \mathrm{CFU}$, with crop and time as explanatory variables. Slope $=-0.0759(\mathrm{SE}=0.0112 ; P<0.001)$ and $\Delta_{\text {intercept }}=$ $0.713(\mathrm{SE}=0.206 ; P<0.01)$.
In all years of the trial, the high apothecia counts expected after the control treatment of bean crops were not realized during the following year (only during the second year). The low apothecia counts were the result of turning soil by ploughing, which buried sclerotia from the bean crop to a depth of 20 to $30 \mathrm{~cm}$, which was too deep for germination and production of apothecia. Ploughing the following year brought the sclerotia to the surface again, which allowed germination. Potato and chicory were grown on ridges, which disrupted the distribution of sclerotia in layers. During the first 5 years, chicory and potato crops were grown during the second and third years, respectively, after bean, so high numbers of apothecia appeared for the first time in control plots with chicory, 2 years after bean, and persisted in subsequent years (Table 3). The commercial potato crop of 1995 assured soil mixing in all plots, which facilitated detection (in different plots) of the 1994 bean treatment effect, as well as the 1993 treatment.

Relationship between infection of sclerotia by $\boldsymbol{C}$. minitans and number of apothecia. During the last year assessed (1996), treatment with $C$. minitans reduced the number of apothecia by $92 \%$ compared with the control and Trichoderma spp. treatments (Table 4 ). On average, $\approx 90 \%$ of the sclerotia samples collected during the experiment were infected by $C$. minitans at the end of the season (Table 5). Infected sclerotia decomposed readily, which was apparent because of the difficulty encountered in collecting sufficient sclerotia on the last sampling date in plots treated with $C$. minitans, which was not encountered in the other treatments. Because numerous sclerotia are formed within the stems and pods of bean, the special sample of such sclerotia in 1992 served as a necessary confirmation that $C$. minitans was able to reach $S$. sclerotiorum even within colonized host tissue $(13,22)$. The good agreement between the percent infection of sclerotia by $C$. minitans on the third sampling date and reduction in number of apothecia in our trial indicates cause and effect.

The failure of Trichoderma spp. treatments. Due to the ineffectiveness of the Trichoderma spp. treatment, it was abandoned after 1992. The Trichoderma spp. isolates used in the trial originated from $S$. sclerotiorum sclerotia, as did the $C$. minitans isolates (10). Trichoderma spp. was not only an ineffective treatment, but on several occasions, it stimulated production or survival of $S$. sclerotiorum sclerotia, resulting in as much as 2.6 times more apothecia compared with the nontreated control in 1994 (Table 4). Also, the yield of dry beans from the Trichoderma spp. treatment, but not the control, was significantly lower than that of the $C$. minitans treatment in 1994 . No reason for this effect can be advanced. Tables 3 and 4 show the after-effects of Trichoderma spp. application on apothecia counts compared with the control. After replacement of Trichoderma spp. in 1993 by a single $C$. minitans application, the ratio of the number of apothecia compared with the control in chicory plots $(0.22)$ is the result of the treatment on bean in 1993. Finally, in 1996 the 3 years of Trichoderma spp. treatments and 2 years of single sprays with $C$. minitans resulted in a level of soil contamination in the Trichoderma spp.-treated plots at least as high as those in the control and a ratio of 1.07 (Table 4).

Potential application of $\boldsymbol{C}$. minitans as a BCA. The reduction of soil contamination with $S$. sclerotiorum sclerotia after $C$. minitans applications makes $C$. minitans a valuable BCA with potential for applications in organic and sustainable leafy crop-growing systems. Whenever a leafy crop shows high disease incidence, spraying with the mycoparasite before turning crop residues into the soil would considerably reduce survival of sclerotia. Although all crops were treated every year, the results suggest that treatment of only the highly susceptible bean crop with $C$. minitans would have been sufficient to prevent accumulation of sclerotia in soil. Crops such as rapeseed and sunflower probably would have nearly the same multiplicative effect on sclerotia as bean. When disease occurs, such crops should be treated. Apart from being indispensable for organic farmers, a $C$. minitans treatment could play a specific role in an integrated crop management system in which 
spraying with fungicides is limited to high disease risk situations. Finally, if the disease were more severe than expected (e.g., when forecasts based on risk factors at full flowering of rapeseed [23] prove invalid), a treatment with $C$. minitans would not prevent damage to the crop and decreased yield, but it would reduce the potential inoculum available in subsequent years.

Whether a single late application is sufficient requires further study. The survival of conidia on healthy leaves (Fig. 1), which resulted in a $10 \%$ reduction in population size in 2 weeks, suggests that spraying before a disease outbreak, an alternative strategy comparable to preventative fungicide application, may be effective. Early spraying would be an advantage in high, dense crops such as rapeseed. As soon as disease occurs, natural reproduction of $C$. minitans will assure infection of sclerotia successively formed. Preventative use of $C$. minitans would share with chemical preventive sprays a negative impact on economical production but would not have a negative impact on the environment.

\section{ACKNOWLEDGMENTS}

We thank I. Vos and B. Verdam for skillful assistance in field treatments and observations and P. Bleeker and the staff of De Waag for dedicated lay-out and maintenance of the trial. G. J. Bollen, J. Köhl, and P. A. G. Elmer commented on drafts of the manuscript.

\section{LITERATURE CITED}

1. Adams, P. B. 1990. The potential of mycoparasites for biological control of plant diseases. Annu. Rev. Phytopathol. 28:59-72.

2. Adams, P. B., and Ayers, W. A. 1979. Ecology of Sclerotinia species. Phytopathology 69:896-899.

3. Andrews, J. H. 1992. Biological control in the phyllosphere. Annu. Rev. Phytopathol. 30:603-635.

4. Budge, S. P., McQuilken, M. P., Fenlon, J. S., and Whipps, J. M. 1995. Use of Coniothyrium minitans and Gliocladium virens for biological control of Sclerotinia sclerotiorum in glasshouse lettuce. Biol. Control 5:513-522.

5. Chou, M. C., and Preece, T. F. 1968. The effect of pollen grains on infections caused by Botrytis cinerea Fr. Ann. Appl. Biol. 62:11-22.

6. Expert, J. M., and Digat, B. 1995. Biocontrol of Sclerotinia wilt of sunflower by Pseudomonas fluorescens and Pseudomonas putida strains. Can. J. Microbiol. 41:685-691.

7. Fokkema, N. J., Gerlagh, M., Köhl, J., Jongebloed, P. H. J., and Kessel, G. J. T. 1994. Prospects for biological control of foliar pathogens. Brighton Crop Prot. Conf. Pests Dis. 3:1249-1258.

8. Gerlagh, M., Goossen-van de Geijn, H. M., Verdam, B., and Fokkema, N. J. 1995. Biological control of white mould (Sclerotinia sclerotiorum) in various crops by application of Coniothyrium minitans. IOBC Bull. 18(3): $13-17$

9. Gerlagh, M., van de Geijn, H. M., and Verdam, B. 1993. Microbial suppression of viable sclerotia of Sclerotinia sclerotiorum and white mould disease in field crops. 16(11):64-68.

10. Gerlagh, M., and Vos, I. 1991. Enrichment of soil with sclerotia to isolate antagonists of Sclerotinia sclerotiorum. Pages 165-171 in: Biotic Interactions and Soil-borne Diseases. A. B. R. Beemster, G. J. Bollen, M. Gerlagh, M. A. Ruissen, B. Schippers, and A. Tempel, eds. Elsevier Science Publishing Co., Amsterdam.

11. Gerlagh, M., Whipps, J. M., Budge, S. P., and Goossen-van de Geijn, H. M. 1996. Efficiency of isolates of Coniothyrium minitans as mycoparasites of Sclerotinia sclerotiorum, Sclerotium cepivorum and Botrytis cinerea on tomato stem pieces. Eur. J. Plant Pathol. 102:787-793.

12. Hannusch, D. J., and Boland, G. J. 1996. Influence of air temperature and relative humidity on biological control of white mold of bean (Sclerotinia sclerotiorum). Phytopathology 86:156-162.

13. Huang, H. C. 1977. Importance of Coniothyrium minitans in survival of sclerotia of Sclerotinia sclerotiorum in wilted sunflower. Can. J. Bot. 85: 289-295.

14. Huang, H. C. 1980. Control of Sclerotinia wilt of sunflower by hyperparasites. Can. J. Plant Pathol. 2:28-32.

15. Huang, H. C., Kokko, E. G., and Erickson, R. S. 1997. Infection of alfalfa pollen by Sclerotinia sclerotiorum. Phytoparasitica 25:17-24.

16. McCullagh, P., and Nelder, J. A. 1989. Generalized Linear Models. 2nd ed. Chapman and Hall, London.

17. McLaren, D. L., Huang, H. C., and Rimmer, S. R. 1996. Control of apothecial production of Sclerotinia sclerotiorum by Coniothyrium minitans and Talaromyces flavus. Plant Dis. 80:1373-1378.

18. McQuilken, M. P., Budge, S. P., and Whipps, J. M. 1997. Biological control of Sclerotinia sclerotiorum by film-coating Coniothyrium minitans on to sunflower seed and sclerotia. Plant Pathol. 46:919-929.

19. McQuilken, M. P., Mitchell, S. J., Budge, S. P., Whipps, J. M., Fenlon, J. S., and Archer, S. A. 1995. Effect of Coniothyrium minitans on sclerotial survival and apothecial production of Sclerotinia sclerotiorum in fieldgrown oilseed rape. Plant Pathol. 44:883-896.

20. Sandys-Winsch, C., Whipps, J. M., Gerlagh, M., and Kruse, M. 1993. World distribution of the sclerotial mycoparasite Coniothyrium minitans. Mycol. Res. 97:1175-1178.

21. Soil Survey Staff. 1990. Keys to Soil Taxonomy. 4th ed. SMSS Technol. Monogr. 19. Virginia Polytechnic Institute \& State University, Blacksburg.

22. Trutmann, P., Keane, P. J., and Merriman, P. R. 1982. Biological control of Sclerotinia sclerotiorum on aerial parts of plants by the hyperparasite Coniothyrium minitans. Trans. Br. Mycol. Soc. 78:521-529.

23. Twengström, E., Sigvald, R., Svensson, C., and Yuen, J. 1998. Forecasting Sclerotinia stem rot in spring sown oilseed rape. Crop Prot. 17:405-411.

24. Whipps, J. M., and Budge, S. P. 1990. Screening for sclerotial mycoparasites of Sclerotinia sclerotiorum. Mycol. Res. 94:607-612.

25. Whipps, J. M., and Gerlagh, M. 1992. Biology of Coniothyrium minitans and its potential for use in disease biocontrol. Mycol. Res. 96:897-907. 